\title{
Análisis bacteriológico del arroz con leche expendido en el Área Metropolitana de Costa Rica
}

\author{
Freddy Carranza ${ }^{1}$, Pablo Rivera ${ }^{1}$, Carolina Chaves ${ }^{1,2}$ y María Laura Arias ${ }^{1,2}$ \\ 1. Facultad de Microbiologia, Universidad de Costa Rica; maria.ariasechandi@ucr.ac.cr \\ 2. Centro de Investigación en Enfermedades Tropicales, Universidad de Costa Rica
}

Recibido 11-XII-2012 Corregido 5-III-2013 Aceptado 2-IV-2013

\begin{abstract}
Bacteriological analysis of rice pudding expended in the metropolitan area of Costa Rica. Costa Ricans frequently consume rice pudding that can be prepared either industrially or by artisanal means. In order to evaluate its bacteriological quality, 50 industrial samples and 30 artisanal samples were analyzed. We considered shelf life, contamination and manipulation indicators, and the presence of potential pathogens, including Staphylococcus aureus, Listeria monocytogenes and Bacillus cereus. We determined the presence of genes (nheA, B and C) for the Bacillus cereus strains using the polymerase chain reaction technique (PCR). $38 \%$ of the industrial origin samples and $70 \%$ of the artisanal ones showed an aerobic mesophilic total plate count over $10^{4} \mathrm{CFU} / \mathrm{g}, 6 \%$ of the industrial samples and $40 \%$ of the artisanal ones showed lactic bacteria counts over $104 \mathrm{CFU} / \mathrm{g}$. Total coliforms were over $100 \mathrm{MPN} / \mathrm{g}$ in $14 \%$ of the industrial origin samples, and in $70 \%$ of the artisanal ones. Similarly, $8 \%$ of industrial samples and $60 \%$ or artisanal samples presented a most probable number of fecal coliforms over 100. Nevertheless, Escherichia coli was only isolated from $6 \%$ of industrial samples and 3,3\% of artisanal ones. B. cereus was recovered and identified in $8 \%$ of the industrial samples and from $13 \%$ of the artisanal ones. The presence of genes nheA, $B$ and $C$ was detected in 3 of the strains isolated from industrial samples and all the strains isolated from the artisanal ones. Staphylococcus aureus and Listeria monocytogenes were not isolated.
\end{abstract}

\section{KEY WORDS}

Rice pudding, bacteriological quality, Bacillus cereus, Listeria monocytogenes, nheA, B and C

\section{RESUMEN}

El arroz con leche es un alimento de consumo frecuente en la población costarricense que se prepara artesanal e industrialmente. Con el fin de conocer su calidad bacteriológica, se analizaron 50 muestras de arroz con leche de origen industrial así como 30 muestras del mismo producto pero de origen artesanal. Se realizó la determinación de indicadores de manipulación, contaminación, vida útil y patógenos incluyendo Staphylococcus aureus, Listeria monocytogenes y Bacillus cereus. Además, se determinó la presencia de los genes nheA,B y $C$ en las cepas de Bacillus cereus aislados, esto, utilizando la técnica de reacción en cadena de la Polimerasa (PCR). Un 38\% de las muestras de origen industrial y $70 \%$ de las de origen artesanal mostró un recuento total aerobio mesófilo superior a $104 \mathrm{UFC} / \mathrm{g}$, de la misma manera un $6 \%$ de las muestras de origen industrial y un $40 \%$ de las artesanales mostraron un recuento de bacterias lácticas superior a $10^{4} \mathrm{UFC} / \mathrm{g}$. Con respecto a coliformes totales, $14 \%$ de las muestras industriales y $70 \%$ de las artesanales superaron los $100 \mathrm{NMP} / \mathrm{g}$. Un $8 \%$ de las muestras de origen industrial y $60 \%$ de las de origen artesanal presentó un NMP de coliformes fecales superior a 100. Se confirmó la presencia de Escherichia coli en $6 \%$ de las muestras industriales y 3,3\% de las artesanales). Se pudo recuperar e identificar Bacillus cereus en un $8 \%$ de las muestras de origen industrial y en $13 \%$ de las de origen artesanal. En tres de las cepas de origen industrial y todas las de origen artesanal se determinó la presencia de genes nheA, nheB y nheC No se detectó la presencia de Staphylococcus aureus ni de Listeria monocytogenes.

\section{PALABRAS CLAVE}

Arroz con leche, calidad bacteriológica, Bacillus cereus, Liseria monocytogenes, nheA, B and C
El arroz con leche es un producto tradicional de la cocina costarricense, es de consumo frecuente, y puede ser preparado de manera artesanal o industrialmente. Este postre se elabora a partir de ingredientes tanto de origen lácteo así como de granos y especias. Las características de $\mathrm{pH}$, humedad favorecen la multiplicación bacteriana (Papageorgiou, Melas \& Koutsoumanis, 2003) por lo cual se ha visto involucrado en brotes de origen alimentario (Kamga et al., 2007). Así mismo, el proceso de elaboración de este producto puede contribuir de manera significativa a la diseminación de microorganismos patógenos. 
Las enfermedades transmitidas por alimentos (ETA's) constituyen uno de los problemas sanitarios más comunes en el ámbito mundial y que mayor impacto tiene en la salud de las personas. Una estimación de la mortalidad anual por ETA en los países en desarrollo indica 2,1 millones de defunciones, en su mayoría lactantes y niños (Mejía, Murillo, Suazo \& Campos, 2009).

Debido al agitado ritmo de vida actual, este tipo de enfermedades se relaciona con servicios de alimentación donde se expenden comidas preparadas, tales como servicios de comida rápida, restaurantes, cafeterías y escuelas, entre otros (Ray \& Bhunia, 2008).

El análisis microbiológico de alimentos busca asegurar la inocuidad de estos y detectar la presencia de bacterias potencialmente productoras de cuadros de intoxicación, de toxi-infección y de infección (Arias \& Antillón, 2000).

Por las características de este platillo, los microorganismos patógenos que más se asocian son Staphylococcus aureus y Bacillus cereus (Bustos, 2000). Actualmente, se incluye también el análisis de Listeria monocytogenes debido a su amplia distribución en la naturaleza (Cisternas et al., 2002), su asociación a productos alimentarios, en especial a lácteos (Rossi, Paiva, Tornese, Chianelli \& Troncoso, 2008) y al grave problema que representa esta bacteria para las industrias alimentarias debido a la dificultad que presenta su control, siendo un organismo prioritario en los planes de análisis de peligros y puntos críticos de control (López, Suárez, Chico-Calero, Navas \& Martínez, 2006).

Con el fin de caracterizar desde el punto de vista microbiológico la calidad del arroz con leche distribuido en el Area Metropolitana de San José, Costa Rica y tomando en cuenta muestras artesanales, a las cuales no se les ha agregado ningún agente conservador, así como muestras de origen industrial (con conservador y mantenidas en refrigeración), se realizó el presente estudio, en el cual se evaluó la potencial presencia de bacterias patógenas asociadas, su contaminación con coliformes totales, fecales y Escherichia coli, la presencia de Staphylococcus aureus como indicador de mala manipulación y el recuento de bacterias lácticas como uno de los indicadores de vida útil asociado.

\section{MATERIAL Y MÉTODOS}

\section{Origen de las muestras}

Se analizaron 50 muestras de arroz con leche de origen industrial y seleccionadas al azar que se compraron en distintos supermercados del país, durante un periodo de un año y medio así como 30 muestras del mismo producto pero de origen artesanal, provenientes de restaurantes de los cantones de Alajuela, Atenas, Goicoechea, Moravia y
San José. Todas las muestras fueron transportadas en frío y analizadas en menos de $24 \mathrm{~h}$ en las instalaciones del Laboratorio de Microbiología de Alimentos (LAMA) de la Facultad de Microbiología, Universidad de Costa Rica.

\section{Análisis microbiológico}

Las muestras fueron analizadas mediante recuento total aerobio mesófilo, recuento de bacterias lácticas y número más probable (NMP) de coliformes totales, coliformes fecales y Escherichia coli. Se evaluó también el NMP de Staphylococcus aureus como indicador de manipulación y la presencia/ausencia de Bacillus cereus y de Listeria monocytogenes como potenciales patógenos asociados al alimento.

\section{Preparación inicial de las diluciones}

Se pesaron 25 gramos de cada muestra y se le agregaron 225mL de Agua Peptonada Estéril (APE) al 0,1\% los cuales fueron homogeneizados utilizando un Stomacher y que representan la primera dilución $10^{-1}$. A partir de ésta se prepararon diluciones seriadas decimales hasta $10^{-5}$.

\section{Recuento Total Aerobio Mesófilo (Pouch \& Ito, 2001)}

Se tomó $1 \mathrm{~mL}$ de las diluciones previamente preparadas y se inoculó en placas de Petri estériles rotuladas. A cada placa se le agregó Agar Estándar +2,3,5-cloruro de Trifenil Tetrazolium (TTC). Seguidamente se incubaron las placas a $35^{\circ} \mathrm{C}$ por $48 \mathrm{~h}$ en atmósfera aerobia.

\section{Recuento de bacterias ácido lácticas (Pouch \& Ito, 2001)}

Se tomó 0,1 $\mathrm{mL}$ de cada dilución preparada y se esparció en placas con Agar Man, Rogosa y Sharpe (MRS). Las placas se incubaron de forma invertida, a temperatura ambiente y en capnofília durante 5 días a $20^{\circ} \mathrm{C}$. Se hizo una confirmación presuntiva mediante tinción de Gram y prueba de catalasa.

\section{Número Más Probable para coliformes totales y fecales}

Se siguió la metodología descrita por Pouch con pequeñas modificaciones como se describe a continuación (Pouch \& Ito, 2001). Se tomó $1 \mathrm{~mL}$ de las diluciones descritas anteriormente y se inocularon por triplicado en serie de tres tubos de Caldo Lactosado Simple con campana Durham invertida. Los tubos se incubaron a $35^{\circ} \mathrm{C}$ por $48 \mathrm{~h}$ en aerobiosis como prueba presuntiva. Para las pruebas 
confirmatorias se utilizó Caldo Bilis Verde Brillante con campana Durham incubado a $35{ }^{\circ} \mathrm{C}$ por 48 para coliformes totales y Caldo Escherichia coli con campana Durham invertida incubado a $44,5^{\circ} \mathrm{C}$ por $24 \mathrm{~h}$ para coliformes fecales. A los tubos EC positivos se les realizó una prueba de indol con el fin de determinar el NMP de E. coli.

\section{Número Más Probable de Staphylococcus aureus}

Se siguió la metodología descrita en el Bacteriological Analytical Manual del FDA por Bennett \& Lancette (2001). Brevemente, se tomó $1 \mathrm{~mL}$ de las diluciones previamente preparadas se inoculó en series de tres tubos de Caldo Tripticasa Soya con $10 \%$ de $\mathrm{NaCl}$. Se incubaron a $35^{\circ} \mathrm{C}$ por 48h. Los tubos que presentaron crecimiento y turbidez fueron rayados en placas de Agar Baird Parker e incubados a $35^{\circ} \mathrm{C}$ por $48 \mathrm{~h}$. La confirmación presuntiva fue realizada mediante tinción de Gram y prueba de coagulasa.

\section{Presencia de Listeria monocytogenes en $\mathbf{2 5} \mathrm{g}$ del alimento}

Se utilizó el procedimiento de aislamiento por Pagotta FDA (1995). Se pesaron $25 \mathrm{~g}$ de muestra y se le agregaron $225 \mathrm{~mL}$ de Caldo Listeria. Se incubó a $35^{\circ} \mathrm{C}$ por $48 \mathrm{~h}$. Se tomó $0,1 \mathrm{~mL}$ de este preenriquecimiento, se esparció en placas de Agar Oxford y se incubó por $48 \mathrm{~h}$ a $35^{\circ} \mathrm{C}$. Las pruebas confirmatorias incluyeron la tinción de Gram, prueba de catalasa positiva, prueba de CAMP en agar sangre en punta de flecha, movilidad en sombrilla a $25^{\circ} \mathrm{C}$ en agar movilidad, fermentación de Ramnosa y no de Xilosa, y luz de Henry positiva.

\section{Determinación de Bacillus cereus y evaluación de su carácter toxigénico}

Se siguió la metodología descrita en Pouch \& Ito (2001). Brevemente, se tomó $1 \mathrm{~mL}$ de las diluciones previamente preparadas y se inoculó en series de tres tubos de Caldo Tripticasa Soya con Polimixina y se incubó por $48 \mathrm{~h}$ a $35^{\circ} \mathrm{C}$. Posteriormente se tomó $0,1 \mathrm{~mL}$ de cada tubo y se rayó en placas de Agar Manitol Yema de huevo Polimixina (MYP) las cuales se incubaron invertidas por $24 \mathrm{~h}$ a $35^{\circ} \mathrm{C}$ en aerobiosis. La confirmación de las colonias sospechosas se llevó a cabo utilizando el sistema automatizado de identificación microbiana Vitek ${ }^{\circledR}$ (Biomerièux).

Se realizó un estudio adicional para la determinación de los genes nheA, B y $C$ en las cepas de Bacillus cereus aislados, utilizando la técnica de reacción en cadena de la Polimerasa (PCR), tal como se describe a continuación:

\section{Extracción de ADN}

La extracción de ADN se realizó de acuerdo a la metodología descrita por Blanco, Arias, Pérez, Rodríguez \& Chaves (2009) utilizando el equipo MagNA Pure LC 2.0 (Roche). Para ello, se realizó una pre-lisis de 10 minutos a $70^{\circ} \mathrm{C}$, en un tubo de $1,5 \mathrm{~mL}$ con $130 \mu \mathrm{L}$ de buffer de lisis (isotiocianato de guanidium), $20 \mu \mathrm{L}$ de proteinasa $\mathrm{K}, 100 \mu \mathrm{L}$ de PBS, y un trozo de una colonia crecida en agar sangre. Posteriormente se realizó el protocolo de extracción DNA III para recuperación de ADN bacteriano siguiendo las especificaciones del fabricante, con un volumen de $100 \mu \mathrm{L}$ de elución.

\section{Cebadores}

Se utilizaron los cebadores descritos por Hansen \& Hendriksen (2001) tal y como se describen en la Cuadro 1.

\section{Amplificación}

Se llevó a cabo el protocolo de amplificación descrito por Blanco et al. (2009). Brevemente, se realizó una mezcla de reacción para múltiplex PCR, conteniendo $1 \mu \mathrm{L}$ de cada primer al $100 \mathrm{uM}, 17 \mu \mathrm{L}$ de agua libre de nucleasas, $25 \mu \mathrm{L}$ de Master Mix $2 X$ (Fermentas $^{\circledR}$ ), y $2 \mu \mathrm{L}$ de ADN. Las condiciones de termociclado fueron: desnaturalización inicial $94^{\circ} \mathrm{C} / 5 \mathrm{~min} ; 30$ ciclos de amplificación de $94^{\circ} \mathrm{C} / 15 \mathrm{~s}$, anillamiento a $55^{\circ} \mathrm{C} / 45$ s y elongación a $72^{\circ} \mathrm{C} / 2$ min; y extensión final de $72^{\circ} \mathrm{C} / 5 \mathrm{~min}$.

Como control positivo se utilizó ADN de Bacillus thuringiensis var. alzawai HD137, y como control negativo ADN de E. coli ATCC 25922.

Los productos se visualizaron en gel de agarosa al $2 \%$ teñida con bromuro de etidio, usando marcador de peso molecular de $50 \mathrm{pb}\left(\right.$ Fermentas $\left.^{\circledR}\right)$.

\section{CUADRO 1}

Secuencia de nucleótidos, posición de los primers utilizados para la detección de genes codificantes para la toxina Nhe A, Nhe B y NheC y tamaño de los productos esperados.

\begin{tabular}{|l|l|c|}
\hline \multicolumn{1}{|c|}{ Resultados } & \multicolumn{1}{|c|}{ Secuencia } & $\begin{array}{c}\text { Producto } \\
\text { esperado }(\mathbf{p b})\end{array}$ \\
\hline nhe 344 S & TACGCTAAGGAGGGGC & 499 \\
\hline nheA 843 A & GTTTTTATTGCTTCATCGGCT & \\
\hline nheB 1500 S & CTATCAGCACTTATGGCAG & 769 \\
\hline nheB 2269 A & ACTCCTAGCGGTGTTCC & \\
\hline nheC 2820 S & CGGTAGTGATTGCTGGG & 581 \\
\hline nheC 3401 A & CAGCATTCGTACTTGCCAA & \\
\hline
\end{tabular}




\section{RESULTADOS}

En el Cuadro 2 se puede observar el resultado obtenido del recuento total aerobio mesófilo (RTAM) y del recuento de bacterias ácido lácticas (RL) para las muestras estudiadas, tanto de origen industrial como artesanal. Para el RTAM el mayor porcentaje de muestras de origen industrial se ubicó entre $10^{4}$ y $10^{5} \mathrm{UFC} / \mathrm{g}$, mientras que en las muestras artesanales, el mayor porcentaje presentó valores superiores a $10^{5} \mathrm{UFC} / \mathrm{g}$. En el caso del RL, la mayoría de las muestras industriales presentaron valores entre $10^{2} \mathrm{y}$ $10^{3} \mathrm{UFC} / \mathrm{g}$, en tanto que en las artesanales $30 \%$ presentó valores superiores a $10^{5} \mathrm{UFC} / \mathrm{g}$.

En el recuento de coliformes totales, se encontró que un $38 \%$ de las muestras de origen industrial y $30 \%$ de las de origen artesanal fueron negativas para este parámetro $(>3$ $\mathrm{NMP} / \mathrm{g}$ ) No obstante, en $14 \%$ de las muestras industriales y $70 \%$ de las artesanales este valor superó los $100 \mathrm{NMP} / \mathrm{g}$.

Los análisis de coliformes fecales para muestras de origen industrial determinaron un $26 \%(n=13)$ de muestras con valores $>3 \mathrm{NMP} / \mathrm{g}$, pero sólo el $8 \%(n=4)$ mostraron valores sobre los $100 \mathrm{NMP} / \mathrm{g}$. En cuanto a la confirmación de la presencia de Escherichia coli, se determinó este microorganismo en un $6 \%(n=3)$ de las muestras analizadas. De manera contrastante, $60 \%$ de las muestras de origen artesanal mostraron valores sobre los $100 \mathrm{NMP} / \mathrm{g}$ para coliformes fecales, únicamente se confirmó la presencia de E. coli en una muestra.

Se detectó la presencia de Staphylococcus aureus solo en una muestra de origen artesanal. No fue posible detectar la presencia de Listeria monocytogenes en ninguna de las muestras evaluadas.

\section{CUADRO 2}

Recuento total aerobio mesófilo y recuento de bacterias ácido lácticas de las muestras de arroz con leche de origen industrial $(n=50)$ y artesanal $(n=30)$ obtenidos en el Área Metropolitana de San José, Costa Rica.

\begin{tabular}{ccccc}
\hline Rango & $\begin{array}{c}\text { Muestras } \\
\text { industriales } \\
\mathrm{RTAM}^{*}(\mathbf{n} \%)\end{array}$ & $\begin{array}{c}\text { Muestras } \\
\text { industriales } \\
\mathrm{RL}^{* *}(\mathbf{n} / \%)\end{array}$ & $\begin{array}{c}\text { Muestras } \\
\text { artesanales } \\
\mathrm{RTAM}^{*}(\mathbf{n} \%)\end{array}$ & $\begin{array}{c}\text { Muestras } \\
\text { artesanales } \\
\mathbf{R L}^{* *}(\mathbf{n} / \%)\end{array}$ \\
\hline$<10$ & $8(16)$ & $25(50)$ & - & $6(20)$ \\
$10-10^{2}$ & $2(4)$ & $8(16)$ & - & $3(10)$ \\
$10^{2}-10^{3}$ & $12(24)$ & $9(18)$ & - & $9(30)$ \\
$10^{3}-10^{4}$ & $9(18)$ & $5(10)$ & $9(30)$ & - \\
$10^{4}-10^{5}$ & $19(38)$ & $3(6)$ & $3(10)$ & $3(10)$ \\
$>10^{5}$ & - & - & $18(60)$ & $9(30)$ \\
*RTAM = Recuento Total Aerobio Mesófilo \\
**RL = Recuento de bacterias ácido lácticas
\end{tabular}

Se pudo recuperar e identificar Bacillus cereus en un $8 \%$ de las muestras de origen industrial y en $13 \%$ de las de origen artesanal. En tres de las muestras de origen industrial y todas las de origen artesanal se determinó la presencia de genes nheA, nheB y nheC, de acuerdo a los resultados descritos en la Figura 1.

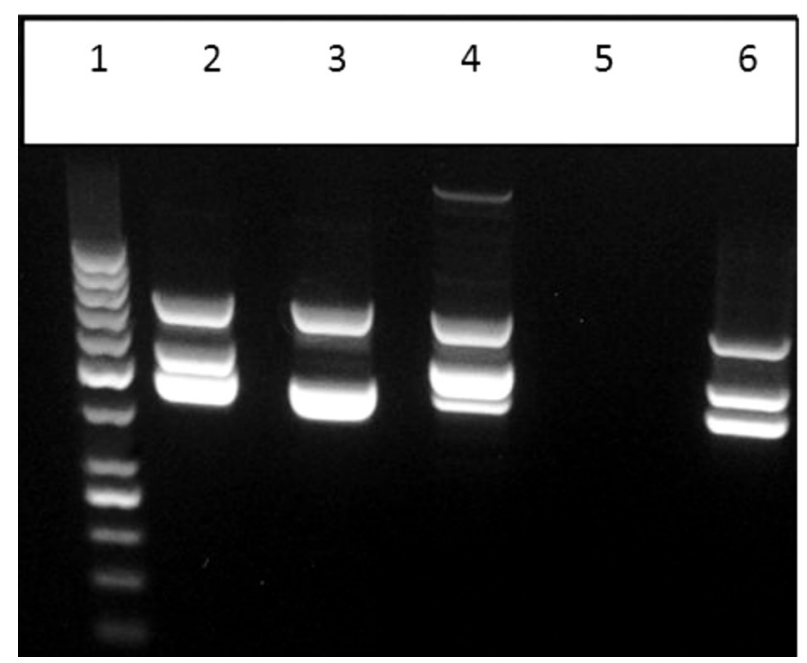

FIG. 1. Determinación de los genes nheA, B y C mediante reacción en cadena de la polimerasa. Carril 1: marcador de peso molecular (50 pb). Carriles 2, 3, 4: muestras 41, 42 y 44 de origen industrial respectivamente. Carril 5: control negativo. Carril 6: control positivo.

\section{DISCUSIÓN}

El análisis microbiológico del arroz con leche se fundamenta en aspectos importantes tales como su composición, preparación y temperatura a la que se almacena y expende.

Los resultados obtenidos en esta investigación se analizaron con los parámetros establecidos en el Decreto Ejecutivo $N^{\circ} 35485$ COMEX-S-MEIC-MAG Reglamento Técnico Centroamericano RTCA 67. 04.50:08 Alimentos: Criterios Microbiológicos para la Inocuidad de los Alimentos (2009). En este decreto se establece que para los alimentos preparados listos para el consumo que no requieren tratamiento térmico, el contenido de Escherichia coli debe ser de $<3 \mathrm{NMP} / \mathrm{g}$, el de Staphylococcus aureus de $<10^{2} \mathrm{NMP} / \mathrm{g}$, y para Listeria monocytogenes se establece que debe estar ausente en $25 \mathrm{~g}$ de producto (Reglamento Técnico Centroamericano RTCA 67.04.50:08 Alimentos: Criterios Microbiológicos para la Inocuidad de Alimentos, 2009). 
Como cualquier otro alimento, el arroz con leche posee microorganismos como flora normal o bien como flora adquirida (Truswell et al., 1978).

Para el caso de productos cocinados, el estándar para recuentos totales aerobios mesófilos indica que el postre no debe superar las $10^{4} \mathrm{UFC} / \mathrm{g}$. En la mayoría de las muestras de origen industrial (38\%), este recuento estuvo entre $10^{4}$ y $10^{5}$ (UFC/g), mientras que, $60 \%$ de las muestras de origen artesanal presentaron valores superiores a $10^{5} \mathrm{UFC} / \mathrm{g}$, lo cual evidencia una carga bacteriana alta en un producto listo para el consumo (Revelli, Sbodio \& Tercero, 2004).

Este efecto puede ser consecuencia de mala calidad de la materia prima, una inadecuada manipulación de los alimentos y/o un almacenamiento inadecuado del producto. En un alimento preparado de origen lácteo, la alta concentración de microorganismos disminuye la vida útil del producto elaborado, desmejora la calidad organoléptica y nutricional e interviene en los procesos de fermentación ácido láctica y en la coagulación enzimática, promoviendo el deterioro o proteólisis de las caseínas (Revelli et al., 2004).

Los recuentos de bacterias lácticas fueron bajos en ambos tipos de muestra, con excepción de 3 muestras de arroz con leche de origen artesanal. Cabe destacar que las bacterias lácticas son capaces de multiplicarse bajo temperaturas de refrigeración, pueden provocar el deterioro a ciertos productos y se ha reportado en la literatura que pueden inclusive reducir a la mitad el periodo de caducidad de un producto empacado (Calleja, Alvarez, Bjorkroth, Capita \& Catalá, 2009).

Por otra parte, los coliformes fecales se mantuvieron por debajo de los 3NMP/g en la mayoría de muestras de origen industrial. Esto evidencia que posiblemente haya una adecuada sanitización en las superficies de contacto de los equipos previo al procesamiento de los alimentos (Pouch \& Ito, 2001). La ventaja de la determinación de estos organismos es que, siendo sensibles a los desinfectantes, sirven como indicador de las condiciones iniciales de procesamiento; además, en alimentos listos para el consumo como en este caso, sirven para mostrar un adecuado proceso de cocción (Pouch \& Ito, 2001).

Las muestras de origen artesanal mostraron un comportamiento completamente diferente con respecto a este parámetro: $60 \%$ presentaron más de 100 coliformes fecales/g. Lo anterior indica que este tipo de arroz con leche es contaminado, probablemente, posterior a su preparación ya que este grupo de microorganismos no resiste las temperaturas de cocción y su presencia en la mayoría de los casos es introducida post-proceso (Girón, 2007).
La presencia de E. coli, el más fidedigno índice de contaminación fecal, sólo fue detectada en un $2 \%$ de las muestras de origen industrial y en el 3,2\% de las muestras de origen artesanal. Con este resultado, se puede inferir que la confirmación de contacto directo o indirecto de las muestras con materia fecal y por tanto, la posibilidad potenciales enteropatógenos, es muy baja (Arias \& Antillón, 2000).

El análisis de Staphylococcus aureus permitió determinar que prácticamente todas las muestras incluidas en el estudio presentaron resultados de $<3 \mathrm{NMP} / \mathrm{g}$ (exceptuando una). Esto revela que posiblemente tanto la materia prima del alimento como el producto acabado posean una adecuada manipulación y un proceso de elaboración con normas de control de higiene adecuadas (Díaz \& González, 2001).

Respecto a Listeria monocytogenes, ésta no se aisló de las muestras evaluadas, lo cual se podría justificar por diversas razones tales como características intrínsecas de la bacteria, la matriz estudiada, la competencia por parte de otros microorganismos en el alimento y tratamiento térmico que se le da al arroz con leche en su elaboración.

La leche, como materia prima del producto, es la fuente de posible contaminación y por tanto del riesgo potencial de listeriosis, pues permite la reproducción de esta bacteria. Sin embargo, en términos generales el nivel de contaminación de ésta es muy bajo (FAO/OMS, 2004), tal y como lo describen Goulet, deVak, Pierre, Strainer \& Rocourt en un estudio realizado en Francia (2001), Schöbitz, Marín, Horzella \& Carrasco en Chile (2001) y Hernadorena \& Elizalde en España (2010).

Cabe destacar que un alto porcentaje de las muestras evaluadas contenían cantidades variables de canela tanto en astilla como en polvo. La canela se ha categorizado como un inhibidor del crecimiento bacteriano, debido a los aceites esenciales propios, en mezclas con diferentes productos volátiles, entre los que se incluyen alcoholes, cetonas y éteres fenólicos, fenoles, ácidos y sus ésteres (Pearson \& Marth, 1990).

Estudios in vitro han demostrado actividad antibacteriana de los aceites esenciales de las especias contra Listeria monocytogenes, Salmonella typhimurium, Escherichia coli O157:H7, Shigella dysenteriae, Bacillus cereus y Staphylococcus aureus, en niveles entre 0,2 a $10 \mu \mathrm{l} / \mathrm{ml}$. (Burt, 2004).

$B$. cereus fue aislado a partir de ambos tipos de muestra pero en cantidades pequeñas. El alimento puede ser considerado seguro para el consumo siempre y cuando la concentración de esta bacteria no supere los $10^{3} \mathrm{UFC/gra-}$ mo (Granum, 2005). Sin embargo, se conoce que la capacidad de $B$. cereus de generar un cuadro clínico radica en la expresión conjunta de los tres genes (nheA, nheB y nheC) es necesaria para la actividad biológica de la enterotoxina 
(Lindbäck, Fagerlund, Skeie \& Einar, 2004). Los hallazgos moleculares de los aislamientos obtenidos en este trabajo evidencian su potencial capacidad toxigénica, pues en todas las cepas excepto una, se obtuvo un resultado positivo para los tres genes.

Los resultados obtenidos en esta investigación permiten inferir que tanto el arroz con leche producido a nivel industrial como el artesanal tiene un bajo riesgo de contener potenciales patógenos. La diferencia más importante entre estos dos tipos de producto radica en la higiene y vida útil asociado, donde las muestras de origen artesanal muestran una menor calidad microbiológica.

\section{REFERENCIAS}

Arias, M.L. \& Antillón, F. (2000). Contaminación microbiológica de los alimentos en Costa Rica. Una revisión de 10 años. Revista Biomédica, 11(2), 113-122.

Bennett, R. \& Lancette, G. (2001). Staphylococcus aureus and staphylococcal enterotoxins. En Compendium of Methods for the Microbiological Examination of Foods. (4ta ed). Washington, D.C.: American Public Health Association.

Blanco, W., Arias, M., Pérez, C., Rodríguez, C \& Chaves, C. (2009). Detección de Bacillus cereus toxigénicos en productos lácteos con especias y leches deshidratadas colectadas en Costa Rica. Archivos Latinoamericanos en Nutrición, 59(4), 402-406.

Burt, S. (2004). Essential oils: their antibacterial properties and potential applications in foods: a review. International Journal of Food Microbiology, 94(3), 223-253.

Bustos, P. (2000). Microbiological quality of dairy deserts manufactured in hotel and catering establishments in the Basque Country in 1999. Alimentaria, 318, 31-33.

Calleja, C., Alvarez, I., Bjorkroth, J., Capita, R \& Catalá, R. (2009). Nuevas tecnologías en la conservación y preservación de los alimentos. Madrid, España: International Marketing \& Communications S.A.

Cisternas, A., Lagos, N., Galstuch, J., González, C., García, C. \& Díaz, J. (2002). Infección por Listeria monocytogenes y embarazo con buen resultado perinatal. Rev. Chil. Obstet. Ginecol, 67(3), 237-241.

Díaz, C. \& González, B. (2001). Staphylococcus aureus en queso blanco y su relación con diferentes microrganismos de calidad sanitaria. Revista de Salud Pública y Nutrición, 2(3), 1-9.

Food and Drug Administration. (1995). Bacteriological and Analytical Manual. AOAC. Nueva York, EEUU.

Girón, A. (2007). Determinación de la calidad microbiológica de la refacción escolar de la escuela pública República Federal de Centroamérica, del municipio de San Lucas Sacatepéquez, Guatemala. (Tesis de Licenciatura). Universidad de San Carlos, Guatemala, Guatemala.
Goulet, V., deVak, H., Pierre, O., Strainer, F \& Rocourt, J. (2001). Effect of prevention measures on incidence of human listeriosis, France, 1987-1997. Journal Emerging Infectious Diseases, 7(6), 983-989.

Granum, P. (2005). Bacillus cereus. En: Foodborne Pathogens: Microbiology and Molecular Biology. UK: Caister Academic Press.

Hansen, B \& Hendriksen, N. (2001). Detection of Enterotoxic Bacillus cereus and Bacillus thuringiensis Strains by PCR Analysis. Applied and Environmental Microbiology, 67(1), 185-189.

Hernadorena, J \& Elizalde S. (2010). Listeria monocytogenes: Incidencia en explotaciones ovinas del País Vasco y Navarra. Navarra Agraria, 5(183), 60-65.

Kamga, G. F., Burckhardt, C. F., Hiller, P., Wichmann, H., Zuschneid, I., Hentschke, J., Hitzbleck, T., Contzen, M., Suckau, M \& Stark, K. (2011). The proof of the pudding is in the eating: an outbreak of emetic syndrome after a kindergarten excursion, Berlin, Germany, December 2007. Surveillance and Outbreak Reports. Euro Surveill, 16(15). Recuperado de http://www.eurosurveillance.org/ViewArticle. aspx?Articleld=19839

Lindbäck, T., Fagerlund, A., Skeie, M \& Einar P. (2004). Characterization of the Bacillus cereus Nhe enterotoxin. Microbiology, 150, 3959-3967

López, V., Suárez, M., Chico-Calero, I., Navas, J \& Martínez, J. (2006). Listeria monocytogenes en alimentos: ¿Son todos los alimentos igual de virulentos? Revista Argentina de Microbiología, 38(4), 224-234.

Mejía, M., Murillo, A., Suazo, H., \& Campos, J. (2009). Brote por Staphylococcus aureus en una guardería infantil en Choluteca, Honduras. Revista Médica Hondureña, 77(2), 67-70.

Papageorgiou, D.D., Melas, A.A., \& K. Koutsoumanis, K. (2003). Growth and survival of Aeromonas hydrophila in rice pudding (milk rice) during its storage at $4^{\circ} \mathrm{C}$ and $12^{\circ} \mathrm{C}$. Food Microbiology, 20, 385-390.

Pearson, L. \& Marth, E. (1990). Inhibition of Listeria monocytogenes by cocoa in a broth medium and neutralization of this effect by casein. Journal of Food Protection, 53, 38-46.

Pouch, F. \& Ito, K. (2001). Compendium of methods for the Microbiological Examination of Foods (4ta ed). Washington, D.C.: American Public Health Association.

Ray, B \& A. Bhunia A. (2008). Fundamentos de Microbiología de los Alimentos (4ta ed). España: McGraw-Hill.

Reglamento Técnico Centroamericano RTCA 67.04.50:08 Alimentos. Criterios Microbiológicos para la Inocuidad de los Alimentos. 2009. Decreto Ejecutivo N 35485 COMEX-S-MEICMAG. Diario Oficial La Gaceta. 2-12, San José, Cost Rica.

Revelli, G., Sbodio, O \& Tercero, E. (2004). Recuento de bacterias totales en leche cruda de tambos que caracterizan la zona noreste de Santa Fe y sur de Santiago del Estero. Revista Argentina de Microbiología 36 (3), 145-149. 
Rossi, M.A., Paiva, M., Tornese, M., Chianelli, S \& Troncoso, A. (2008). Brotes de infección por Listeria monocytogenes: Una revisión de las vías que llevan a su aparición. Revista Chilena de Infectología, 25(5), 328-335.

Schöbitz, R., Marín, M., Horzella, M \& Carrasco, E. (2001). Presencia de Listeria monocytogenes en leche cruda y quesos frescos artesanales. Agro Sur. 29(2), 23-26
Truswell, A., Asp, N., James, W. \& MacMahon B. (1978). “Conclusions" Proceedings of Marabou Symposium on Food and Cancer. Stockholm: Caslom Press. 
